\title{
Rummet mellem kønnene
}

Af Lilian MunK Rösing

\section{Hpad er der $i$ rummet mellem kønnene? Freud pille sware; et barn. Lacan ville spare; fallos. I forsøget pai at finde en tredje position mellem essentialisme og konstruktidisme, sparer forfatteren til artiklen; kønnet.}

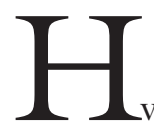

vad er en kvinde?

Et menneske med vagina, bryster, livmoder og en særlig dosis af hormoner? Eller en konstruktion, defineret af en patriarkalsk magtdiskurs, hvor kvinden har fået rollen som ikke-manden: Den kastrerede, den gådefulde, den hysteriske, hullet...? Køber man det første svar og underforstår, at den særligt kropslige konstitution også giver en særlig sjælelig disposition (for omsorg, redebygning osv.), er man essentialist. Køber man det andet, er man konstruktivist. Disse to positioner har i dagens feministiske debat en tendens til at stivne i ufrugtbar antagonisme: konstruktivisterne skaber et spøgelse af en naiv essentialist, der tror, sjælen sidder i hendes livmoder, og essentialisterne skaber et spøgelse af en konstruktivist, der betragter sin cyklus som dikteret af Faderens lov.

Men selve antagonismen, selve forestillingen om at der altid må findes to stridende parter, er en patriarkalsk tankefigur. Lad 
mig med det samme fastslå, at jeg betragter Patriarkatet, ikke som Mandens Herredømme, men snarere som en særlig forestilling om kønsforholdet; en forestilling som både mænd og kvinder er ofre for. Sat på spidsen: Patriarkatet er ikke et system, hvor manden er bøddel og kvinden offer; patriarkatet er et system, hvor både mand og kvinde er ofre for en forvrænget måde at tænke kønsforholdet på. Patriarkatet tænker netop kønsforholdet som en antagonisme, som et magtforhold, hvor den ene må sejre og den anden tabe, én må være bøddel og en anden offer. Den feministiske teori, der tænker forholdet mellem mand og kvinde som et forhold mellem offer og bøddel, fortsætter den patriarkalske tankefigur i stedet for at bryde den.

Hvis antagonismen er Patriarkatets grundfigur, så bliver vejen udaf patriarkatet en nedbrydning af antagonismen. Det vil sige en nedbrydning af en særlig forestilling om relationen mellem to parter. Det, vi skal lære at tænke anderledes, er selve relationen mellem kønnene. For at nedbryde antagonismen, også den mellem essentialisme og konstruktivisme, må vi stille spørgsmålet om kønnet på en ny måde. Ikke: hvad er en kvinde? (eller for den sags skyld: hvad er en mand?), men snarere: hvad er forholdet mellem mand og kvinde?

Jeg vil i det følgende se på nogle symptomatiske svar på spørgsmålet, dvs. nogle svar, som jeg mener præger vores kultur dybt, og som jeg her har fundet i teoretisk aftapning i psykoanalysen ogdekonstruktionen. Mellem kønnene er der "en fallos" ville Lacan svare, eller "den Anden", samtidig med at han ville være enig i Paul de Mans svar: "Ingenting; et hul, en kløft, et tomrum". "Et barn" ville være et af Freuds svar, som også har stor populærpsykologisk udbredelse; det er i barnet, vi realiserer vores parforhold. Endelig ser det ud til, at der implicit i disse forskellige svar ligger en forestilling om, at det der findes mellem kønnene... er kvinden! I det følgende vil jeg forsøge at redegøre for disse forskellige bud på, hvad der er mellem kønnene og samtidig skrive mig frem til mit eget: rummet mellem kønnene som en kontur, hvori kønnet først overhovedet opstår som noget andet og mere end biologisk essens eller socialt konstrukt.

\section{FAllos OG DEN ANDEN}

Lacans fallos er en glidende signifiant, som ikke har ét bestemt sted eller én bestemt definition. Dens definition er for så vidt netop, at den ikke har noget bestemt sted. Fallos er tegnet for en helhed, som vi begærer, men som vi aldrig kan opnå, fordi vi alle er kastrerede. Den lacanianske kastration gælder både mænd og kvinder, idet den ikke skal forstås konkret som en mangel på penis, men som en mere abstrakt, eksistentiel mangel. At være subjekt er for Lacan at være defineret af en mangel, som man i kort begreb må forstå som begxrets uopfyldelighed og dødens uafvendelighed. Fallos er, netop det som ingen af os har, tegnet for selve denne mangel.

Den lacanianske fallos er altså defineret ved adskillelse; den er dermed strukturelt analog med de partialobjekter, som Freud i "Lille Hans" ud fra det infantile perspektiv definerer som "dem der kan adskilles fra kroppen": penis, faeces, babyer (Freud 1909 og 1941). Men som Elizabeth Grosz påpeger $\mathrm{i}$ sin feministiske introduktion til Lacan, så er dette syn på penis som noget, der sidder løst bestemt af et mandligt og narcissistisk blik: "It is during the identificatory blurring of self andother that (from the boys point of view, at least), the penis becomes regarded as a 'detachable' organ" (Grosz 1990: 117). Hvis penis anskues som noget, der sidder løst, er det fordi, manden kigger på kvindekroppen og spejler sig narcissistisk i den; han ser kvinden som en anden udgave af sig selv: På den ene side en negativ udgave (hun har ikke det, jeg har; penis), på den anden side en potentiel udgave (jeg kan også miste min penis!).

Blandt de skiftende pladser, fallos indta- 
ger i det symbolske, er rummet mellem kønnene. I "La signification de phallus" ligner Lacan fallos med et "kopula", et bindeled, hvilket vi både skal forstå fysisk: Fallos som det der forener kønnene i kopulationen og lingvistisk: Fallos som en bindestreg (Lacan 1973: 154). Lad os et øjeblik standse signifianternes glidende kæde og læse dette som et bud på, hvad der kan tænkes at findes mellem kønnene: En fallos.

Hvad vil det sige? Hvad er denne fallos mellem kønnene? I definitionen af fallos som copula kvier Lacan sig ikke ved at fremmane det fysiske billede af den kopulerende penis. Og det er utvivlsomt én af fallos' figurer; det potente, erigerede organ. Kastrationen, eller fallos' fantasmatiske karakter, kommer således til at betegne det faktum, at erektionen ikke varer evigt. Distinktionen mellem fallos og penis er i denne seksuelle metaforik distinktionen mellem det fantasmatiske, evigt erigerede organ og den virkelige penis, hvis erektion aftager.

Men samtidig med at fallos gøres til potensens figur, gøres den til noget så undseligt som en bindestreg. Hvis fallos ophøjes til kønsforbindelsens potente organ, mistes den i samme bevægelse, bliver til intet andet end en bindestreg. Her er der klogskab at hente hos Lacan, hvis man vel at mærke læser hans teori om den symbolske orden som en beskrivelse af patriarkatets misere og ikke som en ophøjelse af denne orden til evig, urokkelig lov. Som deskription er Lacans indsigt i sammenfaldet mellem fallos og kastration skarpsindig. Et sammenfald der kan sættes endnu mere på spidsen som sammenfaldet mellem evig potens og kastration. Fallos er den tabte penis, for fallos er tabet af erektionens aftagen, som er et væ-senstræk ved penis. At ophøje fallos til kønsforbindelsens organ er også at reducere den til rent og skært medium: "it serves to connect two terms together while disappearing or evacuating itself of any identity of its own" (Grosz 1990: 125).

Hvis forbindelsen mellem de to køn udgøres af fallos, så er det et tegn, der ensi- digt udgår fra mandekroppen, så er relationen mellem kønnene defineret af mandens begær, så er forholdet mellem mand og kvinde et forhold mellem subjekt og objekt. Så befinder vi os med andre ord midt i den patriarkalske kønsmisere. Patriarkatets mand lider under den forestilling, at det kun er gennem sin erigerede penis, han kan træde i forhold til kvinden. Og det er synd, ikke mindst for ham selv. Fallos kastrerer både mand og kvinde, fordi den lader både mande- og kvindekønnet fremstå som en mangel: Kvinden er et hul, som må fyldes med mandens penis, og manden er intet $\mathrm{i}$ sig selv, eksisterer kun i sin erigerede tilstand rettet mod kvinden.

Elizabeth Grosz påviser, hvordan det at sætte tegnet "fallos" mellem kønnene er en operation i overensstemmelse med den patriarkalske dikotomiske tankegang. Selv om fallos hævdes at være figur for en kastration, der rammer begge køn, organiserer den betydning ud fra forskellen "at have" eller "ikke at have":

I will claim that the phallic signifier is not a neutral "third" term against which both sexes are analogously or symmetrically positioned. The relation between the penis and phallus is not arbitrary, but socially and politically motivated. The two sexes $[. .$.$] are$ distinguished not on the basis of (Saussurian 'pure') difference, but in terms of dichotomous opposition or distinction; not, that is, as contraries (' $A$ ' and ' $B$ '), but as contradictories ('A' and 'not-A'). [...]Distinctions, binary oppositions, are relations based on one rather than many terms, the one term generating a non-reciprocal definition of the other as its negative. The presence and absence of one term defines both positions in the dichotomy (Grosz 1990:124).

Lader vi fallos glide videre, så indtager den i Lacans symbolske orden også en anden interessant plads; kvindens. I den symbolske orden er manden defineret ved at have fallos, mens kvinden er defineret ved at pare 


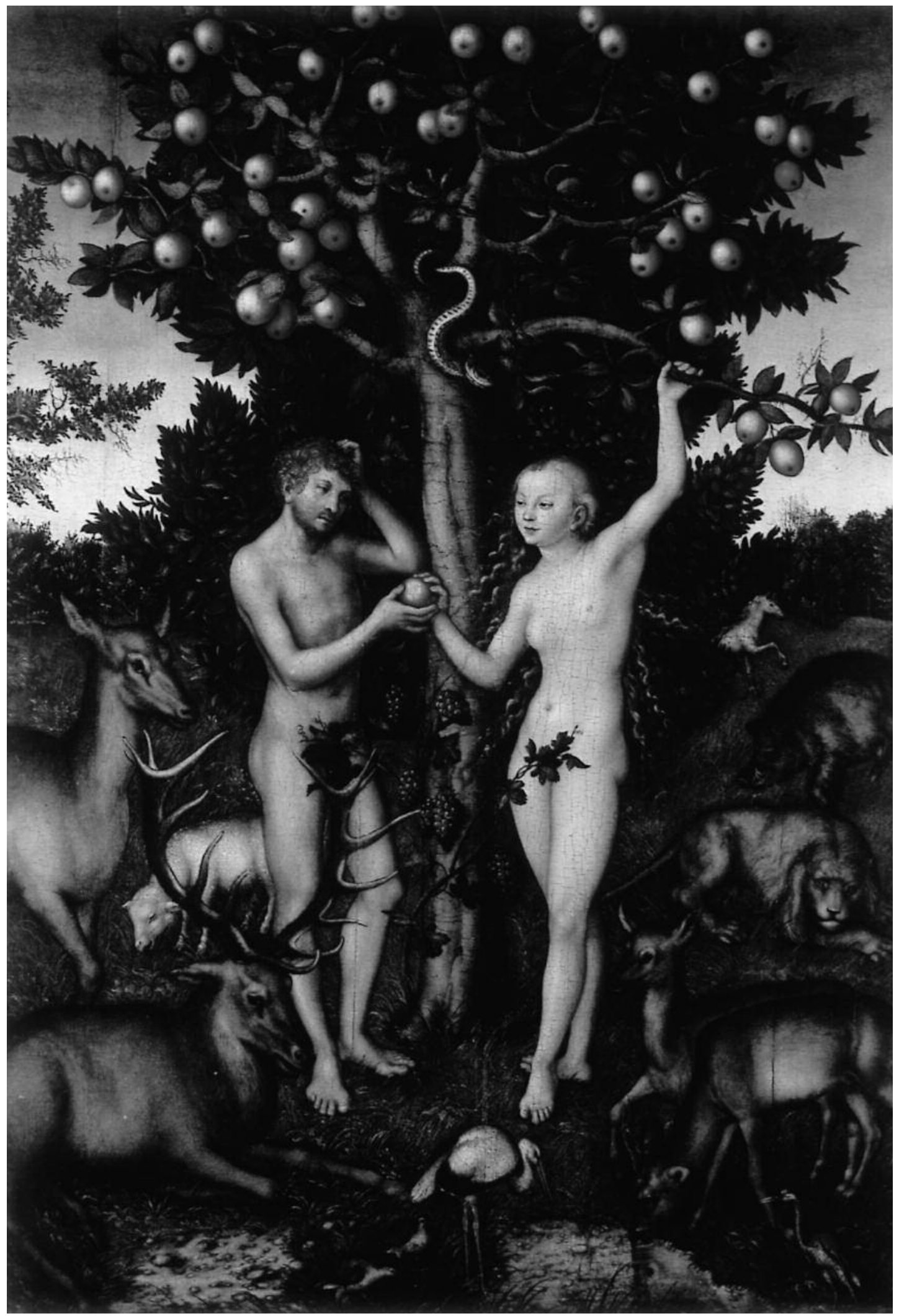


fallos, (hvilket samtidig betyder at have henholdsvis være manglen, men det vender jeg tilbage til). Begæret er for Lacan tragisk, fordi dets opfyldelse er kastrerende for begge køn: Når begæret er opfyldt, har manden ikke længere fallos (erektionen aftager), og kvinden er ikke længere fallos (det begærede objekt). Dette er en præcis beskrivelse af et narcissistisk, don juanistisk begær, som guderne skal vide er vor kulturs norm - men Lacan ophøjer det til det universale, og det er her, han bliver problematisk. Lacan undslipper essentialismen ved at situere sine begreber i den symbolske orden, som jo netop er et kulturelt tegnsystem frem for en naturlov - men samtidig universaliserer han den symbolske orden og udelukker muligheden af, at vi skulle kunne overskride den og så er den lige så tvingende som en naturlov. Med andre ord: Lacan er bevidst om, at Patriarkatet er et kulturelt system, men samtidig udelukker han muligheden for, at dette system skulle kunne overskrides.

Fallos er altså ét af de lacanianske billeder på rummet mellem kønnene. Et andet er som nævnt Den Anden. Den anden (med lille) er det andet subjekt, som jeg kan spejle mig i. Den Anden (med stort) er derimod den absolut Anden, den jeg ikke kan kende, den jeg ikke kan identificere mig med, den hvis viden og erfaring overskrider min egen. Den Andens plads kan indtages af forskellige figurer: Gud, Kvinden, det ubevidste. I én af sine figurer er Den Anden "det subjekt som antages at vide". Det kan tage skikkelse af Gud (som ser alt og ved alt), af Mor (som kender mig bedre end jeg selv), af psykoanalytikeren (som sikkert kan stille en diagnose bare ved at lytte til mig i to minutter), og naturligvis af den jeg er forelsket i (som kan se langt ind $\mathrm{i}$ min sjæl).

Hvordan kan Den Anden nu blive en størrelse mellem kønnene? Jo, i Lacans opfattelse af kærligheden står Gud så at sige altid mellem manden og kvinden. "The Other always intervenes between the subject and the other", skriver Elizabeth Grosz: "There is no direct, unmediatedrelation between the sexes" (Grosz 1990: 137). Vi må forstå Lacan således: Mit begær efter den anden er altid et begxr efter Den Anden. Jeg begærer i kærligheden mødet med det absolut Andet, med det mystiske og gådefulde eller med den der kan se (mig), som jeg ikke selv kan se (mig). Men der vil altid være en kløft mellem det idealvæsen, jeg ønsker mig - og det pruttende, snorkende, snakkende menneske jeg får.

Med begrebet om "Den Anden" fastholder Lacan tilsyneladende en plads for det, der er absolut anderledes. Men problemet er, at Den Anden er et metafysisk, idealistisk begreb, som faktisk udspringer af en manglende evne til at kunne rumme det anderledes: Det anderledes absoluteres, negativiseres, idealiseres, isoleres i et utilgængeligt rum. Dermed bliver "Den Anden" ikke udtryk for en vilje til at tænke det anderledes, men snarere for en vilje til ikke at tænke det anderledes, kun at tænke det ene, i forhold til hvilket det andet enten må opfattes som spejlbillede eller som ren negativitet.

Hvis vi kunne møde den anden (det andet køn!) som noget andet end et spejl, hvis vi altså kunne etablere en relation af ikke-narcissistisk art til den anden, ville vi slet ikke have brug for Den Anden. Så ville den anden kunne rumme forskellen. Den anden og Den Anden er en dikotomi, der baserer sig på en manglende evne til at favne (køns)forskellen. Fordi der ikke gives plads til forskellen i den spejlende relation til den anden, må forskellen isoleres som absolut forskel og defineres negativt (idealiseres), som det der unddrager sig enhver viden og artikulation. Narcissismeteorien (Heinz Kohut) ville betegne Den Anden som narcissistens "almægtige objekt". Endnu en gang viser Lacans psykoanalyse sig som en narcissisme.

Med begrebet om "Den Anden" idealiserer lacanianismen kvinden og kærligheden. Og unddrager sig dermed kvinden og 
kærligheden. Lacans nihilisme, teorien om den konstitutive mangel, er samtidig en idealisme, for oplevelsen af mangel forudsætter et fantasme om helhed.

Der findes altså en nihilisme, som er en idealisme. Gud er kun død, hvis man savner ham. Jeg har forstået på Slavoj Žižek, at Lacan egentlig ikke er en sådan idealistisk nihilist, men at han er blevet misforstået af lacanianerne:

For at sige det ligeud, så har vi at gøre med en "idealistisk" fordrejning af Lacan. Til denne "idealistiske" begærsproblematik med sin konstitutive mangel må man modstille den "materialistiske" problematik for drifternes Reelle. (Zižek 1998: 34f.) (Min oversættelse)

Det er endnu ikke lykkes mig selv at opspore den sympatiske Lacan, som fremtræeder i Zižeks tekstspejl. Men hvis han findes, så retter min polemik sig ikke mod Lacan, men mod lacanianerne.

Hvad enten det nu er Lacan eller lacanianerne, der har fyldt rummet mellem kønnene med fallos og Den Anden, så synes jeg, det er en rigtig dårlig idé. Eller rettere: Som beskrivelser af den patriarkalske misere er billederne præcise, men som eksistentielle definitioner er de betændte. Hvis patriarkatets antagonisme skal overskrides, må vi tænke et rum mellem kønnene, som ikke er gennemskåret af en fallos eller gennemsyret af Den Anden; af tegnet for et begær, der per definition er uopfyldeligt.

De signifianter, Lacan placerer mellem mand og kvinde, er samtidig de signifianter, han placerer på kvindens plads. Fallos er kopula mellem mand og kvinde, men samtidig er kvinden fallos. Den Anden kommer altid mellem manden og kvinden, men er samtidig også kvinden. I samme greb som kvinden placeres på antitesens plads, gøres hun til medium. I den patriarkalske dikotomi står det mandlige og det kvindelige ikke over for hinanden som to substanser; det kvindelige berøves enhver substans og gøres til rent medium. Hullet

Hvad er der i midten? Der er ingenting. Der er et tomrum, et hul, en mangel. Denne figur turde være let genkendelig som en af patriarkatets klassiske figurer for kvinden: I midten af kvindens krop er der ingenting, hun mangler noget, hun er kastreret. Den kvindelige selvoplevelse kan derimod fortælle, at "hullet" ikke er et ingenting, men et rum. Spørgsmålet er derfor, om alle de teorier der sætter manglen eller bristen eller intetheden i centrum, ikke i virkeligheden er udtænkt af en patriarkalsk bevidsthed, der kun kan se kvinden som kastreret (også selv om de som lacanianerne hævder, at kastrationen rammer både mænd og kvinder)

De dekonstruktive teorier om sproget, der har præget de seneste tiårs litteraturvidenskab, må siges at sætte bristen i centrum. Den litterære dekonstruktions hovednavn, Paul de Man, har således igen og igen forsøgt at vise, hvordan der mellem sproget og virkeligheden, eller mellem tegnet og det betegnede, er en kløft, et gabendetomrum. ${ }^{1}$

I sin analyse af Virginia Woolfs roman To the Lighthouse har Elizabeth Abel forbilledligt vist, hvordan en sådan teori om sproget er patriarkalsk, og hvordan frigørelsen fra patriarkatet omvendt kræver, at vi tænker relationen mellem tegn og referent anderledes. Samt at et nyt perspektiv på forholdet mellem tegn og referent er sammenfaldende med et nyt perspektiv på kvindekroppen (hvilket igen, vil jeg hævde, er sammenfaldende med et nyt perspektiv på relationen mellem mand og kvinde). Det spørgsmål, Abel stiller til Woolfs roman er netop: Hvad er der i midten? I midten af Woolfs roman, som er i tre dele, er der en meget mærkelig del, hvor ingen tilsyneladende er til stede. 1. Del skildrer en sommerdag før 1. verdenskrig, hvor professorfruen Mrs. Ramsay som en anden big mama har samlet venner og familie omkring sig på landet, 3 . del skildrer en sommerdag samme sted efter første verdenskrig, hvor Mrs. Ramsay er 
død, og de væsentligste aktører er hendes mand, søn og datter. Midterdelen skildrer huset på landet, som det står tomt i de mellemliggende år; kun ting og lys og lyde og luftninger, ingen mennesker bortset fra en gammel rengøringskone, som ind imellem kommer for at holde det totale forfald fra døren. Hvor midterdelen som regel læses som en del, der står i tomhedens og fraværets tegn, fokuserer Abel i stedet for på det nærvær, der rent faktisk findes: Den gamle rengøringskone, som "indskriver sporene af kvindeligt arbejde i et blegt, inhumant tekstuelt centrum" (Abel 1989: $63)$.

Hvis man påstår, at det, der er i midten af Woolfs roman, er fravær og tomhed - så er det fordi, man gør sig blind for det diskrete liv og den grøde, der rent faktisk er der. Så er det med andre ord, fordi man er underlagt en patriarkalsk forestilling om mellemrummet som en gabende kløft (og det kan man sagtens være, selv om man er "feminist"!). Denne forestilling påviser Abel som en psykisk struktur i Mrs. Ramsays søn, som han beskrives i del 3. Del 3 handler groft sagt om, hvordan sønnen James og datteren Cam tackler moderens fravær, Mrs. Ramsays død. Sønnen må cutte enhver forbindelse til moderen (altså installere en gabende kløft mellem sig og hende) for at rives ud af den aggressive letargi, han er stivnet i. Datteren Cam kommer derimod aldrig ud af sin tavse melankoli - ifølge Abel netop, fordi hun ikke tilbydes nogen alternativ måde at tænke mellemrummet på. Hun bliver selv mellemrum (fallos, Den Anden...) - den der befinder sig mellem far og søn (helt konkret sidder Cam i en båd mellem sin far og James), på den plads der før var moderens, i en klassisk, patriarkalsk, ødipal konfiguration.

Men kan forbindelsen til en død mor være noget andet end et cut, en gabende kløft? Ja, fordi moderen er fysisk fraværende, behøver hun ikke at være det psykisk. Der findes noget mellem fravær og nærvær, der findes et nærvær i fraværet. Der findes et rum, hvor objektet både er og ikke er. Det er det rum, Winnicott kalder det potentielle rum (se Winnicott 1971). Det er det rum, hvor barnet lærer at håndtere separationen fra moderen. Og det er også sprogets rum: Rummet for et sprog, hvor det betegnede ikke forsvinder, fordi det betegnes, men forbliver nærværende i tegnet. At overvinde de patriarkalske tankefigurer, der installerer kløften i midten, er at tænke noget mellem fravær og nærvær eller hinsides fravær-nærvær-dikotomien. At insistere på smagen af æble i ordet "xble" og lugten af kaffe i ordet "kaffe". At insistere på, at den anden findes og kan være nærværende $\mathrm{i}$ min bevidsthed, også når han eller hun er fysisk fraværende.

Psykologisk finder hullets teori sit udtryk i forestillingen: "Jeg er skilt fra den anden af en gabende kløft". Det er denne forestilling, der igen og igen gøres gxldende for kønsforholdet: "der er ingen relation mellem kønnene", siger Lacan;2 "Mænd er fra Mars og kvinder er fra Venus" siger en populærpsykologisk forfatter. $\mathrm{Vi}$ overvinder aldrig patriarkatet, hvis vi ikke overvinder denne forestilling, som er identisk med hullets teori.

Således mener jeg ikke, at en feministisk teori kan basere sig på bristen, negativiteten. Cecilia Sjöholm gør et sympatisk forsøg på at udlæse en potentiel feminisme, eller et potentielt etisk kønsforhold, ud af Lacans negativitetsbegreb. Sjöholm øjner en mulighed for at læse Lacans teori som "en teori om kønsforskel, hvor netop kvinden peger mod det tomrum, den patriarkale lov forsøger atskjule" (Sjöholm 1999) (Min oversættelse). Således skulle der være et subversivt potentiale i den negativitets position, kvinden har fået tildelt, fordi den peger på, at patriarkatet bygger på et tomrum. Den kvinde, der er henvist til et nihil, kan blive nihilismens bannerfører. Hvis dette skal være kønsfrigørende, må det forudsætte, at nihilismen anskues som et alternativ til patriarkatet. Men er den det? Er nihilismen ikke en dybt patriarkalsk ideologi, 
som netop baserer sig på et fantasme om mangel og intethed, der kun kan opretholdes, fordi der reserveres en position for idealiteten - en position, hvortil kvinden udgrænses, såvel som hun udgrænses til negativiteten.

Man kan vælge at fokusere på kvindekroppens vagina som det "intet", der faktisk er "noget"; den "kastrerethed" som faktisk er en frugtbarhed; det "hul" som faktisk er en livmoder. Men mere frugtbart for kønsfrigørelsen (som både er mandens og kvindens frigørelse fra patriarkatet) er det, hvis vi fokuserer på rummet mellem kønnene som det rum, der under patriarkatet betragtes som en kløft, men som burde ses som et skabelsens sted. Hvordan skal nu det forstås? Er det, der skal skabes mellem kønnene barnet? Nej!

\section{BARNET}

Hvorfor er barnet ikke et godt billede på rummet mellem kønnene? Er det ikke i barnet, kønsforholdet realiserer sig, er det ikke i barnet, det bærer frugt?

Problemet med at sætte barnet i centrum for kønsrelationen er for det første, at det hurtigt placerer os i den rene biologiske essentialisme. Manden realiserer sin mandlighed ved at befrugte kvinden, kvinden realiserer sin kvindelighed ved at bære på barnet. At sige at kønnet realiseres i barnet er det samme som at sige, at mandlighed realiseres i faderskab og kvindelighed i moderskab.

På et mere abstrakt filosofisk plan er problemet, at fastholdelsen af de tre termer mor-far-barn er en fastholdelse af trekanten. Og trekanten kender vi fra Freud og Hegel. Hos Freud er trekanten ødipal og betegner kampen mellem far og søn, hvor moderen reduceres til begærsobjekt. En tankefigur der ikke lader nogen plads til kvinden som subjekt og således ingen plads for den etiske kønsrelation, der må være ensubjekt-til-subjekt-relation. Hos Hegel er trekanten dialektisk i den særligt hegelian- ske hierarkiske dialektik, hvor ånden rejser sig højere og højere gennem syntesens bestandige udligning af forskelle i en bevægelse, hvor kvinden reducereses til medium. ${ }^{3}$ Hegeliansk anskuet er barnet kønsforholdets syntese (hvilket samtidig betyder dets ophævelse), mens mand og kvinde forholder sig til hinanden som tese og antitese. Både den freudianske ødipale og den hegelianske dialektiske trekant fastholder antagonismen eller dikotomien og må betragtes som patriarkalske tankefigurer.

Luce Irigaray har i Konsforskellens etik vist, at vejen ud af patriarkatet må gå gennem en forskydning fra en tre-ledet til en to-ledet dialektik, en forskydning fra trekanten til parret. Hvis forholdet mellem mand og kvinde skal blive et forhold mellem subjekt og subjekt, nytter det ikke at ophæve det i barnets syntese. Mand og kvinde må stå over for hinanden uden barnets bufferzone mellem sig. Det, vi må udforske, er parforholdet, i stedet for at forskyde det til/ophæve det i en tredje term. Irigaray ser kærligheden mellem mand og kvinde som et medium, en oscilleren, en evig vorden, som ikke skal stivne i barnets billede. Det betyder ikke, at kærligheden forsvinder, fordi der fødes et barn, men det betyder, at kærligheden aldrig må erstattes med barnet.

Barnet skal ikke være målet for kønsrelationen, men må gerne fremspringe af den. Mellem mand og kvinde skal der ikke være et barn, men et medium hvor barnet eventuelt kan opstå. For Irigaray er kærligheden en relation mellem elskende, ikke en relation mellem elskende og elsket, subjekt og objekt. Så snart kærligheden udnævner et objekt, en "elsket", er den strengt taget ikke længere kærlighed. Hvis man skal forestille sig et barn som billede på kønsrelationen, skal det være Amor, den lille bevingede putti som er billede på selve kønsrelationen. Men Amor, skriver Irigaray, er elskende, ikke elsket. Når “det elskede barn” sættes på Amors plads, forsvinder kærligheden: 
Den medierende bliver barnet, og ikke længere kærligheden. Sat på kærlighedens plads kan barnet ikke længere være elskende. Det bliver sat i stedet for kærlighedens uophørlige bevægelse. Elsket, uden tvivl. Men hvordan være elsket uden at være elskende? [...] En elsket som er et formål, der erstatter kærligheden mellem mænd og kvinder. En elsket som er villet eller en pligt og et middel til at opnå udødelighed. Fordi de elskende ikke kan opnå den eller stræbe efter den indbyrdes. Det er kærlighedens fallit, også for barnet (Irigaray 1984: 33) (Min oversættelse). ${ }^{4}$

Hvis kærligheden ikke længere er mediet mellem mand og kvinde men skal have et formål (at avle et barn), udskiftes kærlighedens oscilleren med en teleologisk trekant. Problemet i at se barnet som et billede på kønsforholdets realisering er, at barnet bliver et mål, en telos for kønsforholdet. Kønnene retter sig ikke længere mod hinanden i den udveksling, der kan skabe kønnets kontur, men mod barnet. Det er ikke barnet, der skal skabes i kønsforholdet, men kønnet. Kønnet som den kontur jeg nu vil forsøge at skitsere.

\section{KonTUREN}

Mit eget bud på det frugtbare billede på rummet mellem kønnene er konturen. Konturen har sin biologiske metafor ikke i penis, ikke i barnet, men i huden.

Hvad hvis man tænkte sig kønnenes forbindelse, ikke som en mekanisk kobling, der kræver en skrue eller et søm, men som et møde mellem hud? Hvis det nu var selve huden, der var medieringens organ og ikke sømmet, fallos? Hvad hvis kærligheden ikke var begæret efter forening og sammensmeltning, men begæret efter grænsen, at få sin grænse, sin hud at føle? Hvad hvis filosofien kunne tænke sig ikke enheden som det oprindelige, men forskellen? Ikke kroppens substans, men hudens grænse.

Den franske psykoanalytiker Didier Anzi- eu har introduceret det geniale begreb om hud-selvet. I hudens billede er selvet eller subjektet ikke en kerne, ikke et centralt punkt (hvad enten det nu er penis eller livmoder) eller en substans, men en flade, en beholder. Anzieu definerer hud-selvet således:

Med Hud-selvet betegner jeg en figuration som barnet i sin udviklings spædeste faser bruger til at danne sig en forestilling om sig selv som et selv, der rummer psykisk indhold, ud fra sin oplevelse afkroppens overflade (Anzieu 1995: 61) (Min oversættelse). 5

Konturen af dette hud-selv tegnes i berøringen med den anden. Jeg får min hud at føle, når jeg rører ved en anden. En relation til den anden via huden er det biologiske billede på den etiske relation: En relation, hvor grænsen, adskillelsen, er forudsætningen for berøringen, mødet.

Hvis vi overfører figuren til kønsforholdet, betyder det, at også kønnet defineres ved den grænse, der samtidig er et møde et møde med det andet køn. Manden bliver mand i sit møde med kvinden, kvinden bliver kvinde i sit møde med manden. Vel at mærke hvis ingen af parterne kommer skøjtende med en forestilling om en på forhånd givet, substantiel "mandlighed" eller "kvindelighed". Først når vi erfarer forskellen, erfarer vi kønnet. Kønnet er selve den kontur, der aftegner sig mellem mand og kvinde, når de berører hinanden. Mellem kønnene findes en hud, en kontur, som situerer kønnet mellem køn og genus.

\section{Noter}

1. Se eksempelvis de Mans Rilke-læsning i Allegories of Reading, hvor han insisterer på "the inevitable absence of areliable referent", den "loss of substance", der konstituerer Rilkes (og enhver andens) poesi (de Man 1982: 47).

2. Den berømte titel på én af Lacans tekster lyder: "Il n'y a pas de rapport sexuel" 
3. I deres læsninger af Hegels etik-kapitel fra Åndensfanomenologi har hhv. Luce Irigaray (1974) og Kelly Oliver (1996) vist, hvordan kvinden i Hegels kønsetik er mediet for mandens dialektiske bevægelse fra natur til kultur.

4. "Le médiateur devient l'enfant, et non plus l'amour. Occupant la place de l'amour, l'enfant ne peut plus être amant. Il estmis au lieu du mouvement incessant de l'amour. Aimé, sans doute. Maiscomment être aimé sans être amant? [...] Un aimé qui est unefin se substituant à l'amour entre hommes et femmes. Un aimé quiest un vouloir, voire un devoir, et un moyen de gagnerl'immortalité. Les amants ne pouvant y atteindre ou y tendre entre eux.C'est la faillite de l'amour, aussi pour l'enfant" (Irigaray 1984: 33).

5. "Par Moi-peau je désigne une figuration dont le Moide l'enfant se sert au cours des phases précoces de son développementpour se représenter luimême comme Moi contenant les contenuspsychiques, à partir de son expérience de la surface du corps" (Anzieu 1995: 61).

\section{LITTERATUR}

- Abel, Elizabeth (1989): Virginia Woolf and the Fictions ofPsychoanalysis, University of Chicago Press.

- Anzieu, Didier (1995): Le Moi-peau, Dunod, Paris.

- de Man, Paul (1982): Tropes (Rilke), in Allegories of Reading, Yale University Press.

- Freud, Sigmund (1909/1941): Analyse der Phobie einerfünfjährigen Knaben. Gesammelte Werke, Bd VII. Fischer,Frankfurt/M .

- Grosz, Elizabeth (1990): Jacques Lacan. A FeministIntroduction. Routledge, London and New York.

- Irigaray, Luce (1974): Speculum. De l'autre femme. Les Éditions de Minuit, Paris.

- Irigaray, Luce (1984): Éthique de la différence sexuelle.Les Éditions de Minuit, Paris.
· Kohut, Heinz (1973): Narzißmus. Suhrkamp, Frankfurt/M.

- Lacan, Jacques (1973): Det ubevidste sprog. Rhodos, København

- Oliver, Kelly (1996): Antigones Ghost: Undoing Hegels Phenomenology ofthe Spirit, in Hypatia, Indiana University Press

- Sjöholm, Cecilia (1999): Från Oidipus till Antigone, in NyPoetik 1999/9 (under udgivelse), Odense Universitetsforlag.

. Winnicott, D.W. (1971): Playing and Reality, Pelican Books, Harmondsworth.

- Zižek, Slavoj (1998): Fra begæret til driften - eller hvorforLacan ikke er lacanianer, in Kritik $1998 / 131$

\section{SUMMARY:}

What is the space between the sexes? Patriarchal theories has (directly and indirectly) defined this space as Phallus, the Other, Nothing, The Child, or even Woman herself. I try to examine these definitions critically while giving my own answer: The space between the sexes is the space that constitutes gender as a kind of phenomenological gender, beyond the dichotomy of "sex" and "gender". That is, gender is the outline between man and woman that defines man and woman respectively; gender (as an existential category) is something that happens in the meeting between man and woman, if we are able to se the other as different as well as similar. The essay is very much inspired by the sexual ethics of Luce Irigaray.

Lilian Munk Rösing, ph.d., forskningsadjunkt, Københavns Universitet 